\title{
In Vitro Models for Neurogenesis
}

\author{
Hassan Azari ${ }^{1,2}$ and Brent A. Reynolds ${ }^{1}$ \\ ${ }^{1}$ Department of Neurosurgery, McKnight Brain Institute, University of Florida, Gainesville, Florida 32611 \\ ${ }^{2}$ Neural Stem Cell and Regenerative Neuroscience Laboratory, Department of Anatomical Sciences \& \\ Shiraz Stem Cell Institute, Shiraz University of Medical Sciences, Shiraz, Iran \\ Correspondence: azarihasan@sums.ac.ir
}

The process of generating new neurons of different phenotype and function from undifferentiated stem and progenitor cells starts at very early stages of development and continues in discrete regions of the mammalian nervous system throughout life. Understanding mechanisms underlying neuronal cell development, biology, function, and interaction with other cells, especially in the neurogenic niche of fully developed adults, is important in defining and developing new therapeutic regimes in regenerative neuroscience. Studying these complex and dynamic processes in vivo is challenging because of the complexity of the nervous system and the presence of many known and unknown confounding variables. However, the challenges could be overcome with simple and robust in vitro models that more or less recapitulate the in vivo events. In this work, we will present an overview of present available in vitro cell-based models of neurogenesis.

\begin{abstract}
The central nervous system (CNS) is one of the most complex and intriguing organs in mammalians, and its development, function, and pathology has attracted the attention of many scientists throughout centuries. One of the amazing phenomena that occur in the CNS is the process of new nerve cell generation or neurogenesis (Morrens et al. 2012; Jessberger and Gage 2014). Neuronal cells are the building blocks of the nervous system, enabling it to establish a highly complex wiring system with the ability to receive, integrate, and respond to a variety of stimuli in a timely and highly organized fashion. Other neural cell types, such as astrocytes and oligodendrocytes, and also the nonneural cells, such as microglia, endothelial, fibroblasts, and blood cells, which are also pres-
\end{abstract}

ent in the CNS, play a significant role in assisting neuronal cells to fulfill their proper function in a homeostatic and balanced microenvironment (Kettenmann et al. 1996; Araque and Navarrete 2010; Perry and Teeling 2013; Zabel and Kirsch 2013). Hence, as neurons are the primary functional units, many of the diseases and disorders of the CNS are associated with neuronal cell loss and dysfunction (Amor et al. 2010). Understanding the root causes and, therefore, finding meaningful therapies for many CNS diseases is dependent on our understanding of the generation of the neuronal cells in association with other cells, mechanisms of their function, maintenance, turnover, and replacement in normal and diseased conditions. Studying all these processes in vivo is a daunting task,

Editors: Fred H. Gage, Gerd Kempermann, and Hongjun Song

Additional Perspectives on Neurogenesis available at www.cshperspectives.org

Copyright (C) 2016 Cold Spring Harbor Laboratory Press; all rights reserved; doi: 10.1101/cshperspect.a021279

Cite this article as Cold Spring Harb Perspect Biol 2016;8:a021279 
considering the complexity and dynamic nature of the nervous system. To facilitate understanding the complex process of neurogenesis, in vitro assays and methodologies have been developed to recapitulate in vivo processes, while at the same time decreasing some of the associated complexities (reductionist approach). In this article, we present an overview of currently available in vitro cell-based neurogenesis models.

\section{IN VITRO NEUROGENESIS MODELS}

Neurogenesis occurs throughout mammalian life, mainly in embryonic, fetal, and neonatal stages and to a lesser extent in the adult stage. In the embryonic development, the backbone of the nervous system is established through formation of neural plate, neural tube, and establishment of the rostrocaudal and anteroposterior patterns (Stiles and Jernigan 2010). In fetal and neonatal stages, the developing nervous system acquires its final shape and in the adult stage, the nervous system is fully established and the process of neurogenesis is limited to certain discrete areas, such as the subventricular zone (SVZ) of the lateral ventricles toward the olfactory bulb (Shen et al. 2008; Kriegstein and Alvarez-Buylla 2009) and subgranular zone (SGZ) of the dentate gyrus (DG) in the hippocampus (Kempermann et al. 2003; Seri et al. 2004). Each one of these stages could be modeled in vitro using pluripotent stem cells and adult neural stem cells (NSCs).

\section{USING PLURIPOTENT STEM CELLS AS AN IN VITRO NEUROGENESIS MODEL}

In vitro models of embryonic neurogenesis and formation of different neuronal phenotypes is mainly based on the usage of pluripotent stem cells, such as embryonic stem cells (ESCs) (Zhang et al. 2001; Schulz et al. 2004; Zeng et al. 2004; Fathi et al. 2015) and induced pluripotent stem cells (iPSCs) (Lu et al. 2013; Compagnucci et al. 2014; Velasco et al. 2014). The ability to differentiate these cells into all three germ layers, namely, the ectoderm, mesoderm, and endoderm, makes pluripotent stem cells a unique cell source to model early stages of nervous system development and studying production of different neuronal subtypes and also finding optimal conditions to generate these cells at a large scale with high purity for cell therapy approaches. Three main culture systems are used to generate neural cells from the pluripotent stem cells, which include embryoid body (EB) formation (Schulz et al. 2003; Elkabetz et al. 2008), coculture with cells, such as bone marrow stromal cells or their conditioned medium that potentiate neuralization processes (Kawasaki et al. 2000; Vazin et al. 2008), and monolayer culture systems (Ying et al. 2003; Gerrard et al. 2005).

\section{Embryoid Body Formation}

Differentiation through EB formation recapitulates embryogenesis of different tissues originating from all three germ layers including primitive neural tissue (Leahy et al. 1999). In the EB, pluripotent stem cells spontaneously differentiate into different cell lineages. Therefore, the resulting neuroepithelial cells need further neural cell selection to enhance their purity. Moreover, the process of neuralization with this approach is lengthy with reduced control over the early phases of the process. Although factors such as retinoic acid (RA) have been used to enhance neural differentiation in the EB (Okabe et al. 1996), this could affect neural patterning and alter the identity of the resulting cells, such as suppression of forebrain neuronal identity (Kawasaki et al. 2000). Hence, the low efficiency of neural conversion, the need for subsequent lineage selection to achieve a final homogeneous neural cell population, and the complexity of multicellular aggregates in the EB approach, makes this culture system difficult for studying cellular and molecular mechanisms underlying neural cell development.

\section{Coculture with Stromal Cells}

Induction of neural identity in mouse ESCs using stromal cells (such as PA6 and MS5) or their conditioned medium has led to the establishment of a serum-free culture system that cir- 
cumvents the need for EB formation and shortens the length of the neuralization process dramatically (Kawasaki et al. 2000; Vazin et al. 2008). The same methodology could also efficiently generate neuroepithelial cells from primate and human ESCs. Moreover, it has been shown that stromal cells can induce the generation of neuroepithelial cells through factors secreted by stromal cells and cell-surface-anchored molecules. Further studies have led to characterization of factors, such as Sonic hedgehog (Shh), which are secreted from stromal cells, and play an essential role in acquiring a dopaminergic phenotype in human ESC (hESC)-derived neural stem cells (Swistowska et al. 2010). Although this methodology is simple, fast, and efficient in generating neuroepithelial cells from murine and human ESCs, the approach is dependent on feeder cells and their unidentified stromalderived inducing activity (SDIA).

\section{Adherent Monolayer Culture System}

In this system of pluripotent stem cells, neural differentiation is based on the idea that early neural induction involves both fibroblast growth factor (FGF) signaling and the inhibition of bone morphogenic protein (BMP) signaling (Linker and Stern 2004). A great body of evidence led to the idea that neural induction and formation of the neural plate occurs as a result of the inhibition of mesoderm and endodermpromoting signals, such as Wnts (via Dkk1), Nodal (via cerberus and lefty), and BMPs (via chordin, noggin, and follistatin) (Levine and Brivanlou 2007). These inhibitory factors are secreted from the organizer region in the developing embryo, resulting in formation of the neural plate. Subsequently, the neural plate begins conformational changes forming the neural groove, the two lateral edges of which move toward each other forming the neural tube. After the initial closure of the neural tube at the future midbrain region, this process progresses cranially to form the forebrain and caudally to establish the hindbrain and spinal cord. Monolayer adherent culture of pluripotent stem cells recapitulate this process in vitro resulting in formation of neural tube-like structures called neural rosettes (Ying et al. 2003; Gerrard et al. 2005; Koch et al. 2009). As this process occurs in a chemically defined serum-free medium, it provides a unique substrate to tease out signaling pathways and complex molecular mechanisms underlying pluripotent stem-cell-derived neurogenesis (Ying et al. 2003). For example, treatment of murine ESCs with factors, such as Dkk1 or lefty, to inhibit Wnt and nodal signaling enhances generation of neuroepithelial cells (Watanabe et al. 2005). In addition, treatment of human ESCs with noggin dramatically reduces contamination of the final neural progenitors with derivatives of the extraembryonic endoderm (Gerrard et al. 2005). This monolayer culture system facilitates visualization of neural conversion of the ES cells and provides researchers with the opportunity to study factors and signaling pathways underlying human neural tube formation, anteroposterior and craniocaudal patterning, and regional neuronal cell specification.

\section{IN VITRO ADULT NEUROGENESIS MODELS}

In vitro models of adult neurogenesis are mainly based on the usage of fetal, postnatal, and adult NSCs. Adult neurogenesis occurs in defined areas of the CNS because of the presence of undifferentiated stem cells known as the NSCs, which are located in very sophisticated organized structures referred to as the NSC niche (Codega et al. 2014).

\section{NSC NICHES AND LESSONS FOR IN VITRO MODELS}

NSCs, as the remnants of the original neuroepithelial cells, reside in special locations, namely, stem-cell niches, along the ventricular neuraxis of the mammalian nervous system (Craig et al. 1996; Golmohammadi et al. 2008; Mirzadeh et al. 2008; Shen et al. 2008; Codega et al. 2014). The adult SVZ stem-cell niche contains three main neural cell types, namely, type B bona fide NSCs (glial fibrillary acidic protein $\left[\mathrm{GFAP}^{+}\right]$-expressing cells) that are quiescent most of the time and, on activation, give rise to type $\mathrm{C}$ transit amplifying cells $\left(\mathrm{GFAP}^{-} / \mathrm{Dlx}^{+}\right)$, 
which are highly proliferative and generate type A neuroblast $\left(\mathrm{GFAP}^{-} / \mathrm{Dlx}^{+} /\right.$doublecortin $^{+}$ $\left[\mathrm{DCX}^{+}\right]$) cells (Chojnacki et al. 2009), which migrate via the rostral migratory stream (RMS) to the olfactory bulb. Apart from bona fide neural stem cells and their progeny, the ependymal cells on the ventricular side and a vascular bed of mainly endothelial cells on the opposite side enclose the niche (Ottone et al. 2014). Moreover, the subventricular stem-cell niches contain a specific type of microglial cells that also play roles in niche function (Marshall et al. 2014). Interactions of the niche resident cells with one another and their microenvironment, as well as the signals from the cerebrospinal fluid (CSF), niche blood vessels surrounding neural networks via axonal terminals, determine the states of quiescence, proliferation, and differentiation in stem-cell progeny and therefore the ongoing neurogenesis process (Silva-Vargas et al. 2013). The converged effect of these different elements in the niche microenvironment influences the maintenance of the stem-cell population and continuous addition of new neuronal cells to the already established neural circuitries in olfactory bulb and dentate gyrus of the hippocampus. Ideally, establishing in vitro models to mimic this myriad of in vivo events is challenging but important to establish a meaningful model. Here, we briefly point out the roles of nonneural resident cells in the SVZ niche.

\section{Ependymal Cells and Neurogenesis}

The SVZ niche is separated from the CSF of the ventricles via a thin layer of multiciliated ependymal cells. Ependymal cells not only act as a physical barrier to protect the niche from noxious substances in the CSF, they serve as a sensor of CSF components through coupling with SVZ astrocytes, and secrete proneurogenic factors, such as noggin to create a favorable neurogenic environment (Lim et al. 2000). The apical region of the ependymal cells facing the neurogenic regions of the SVZ, but not the SGZ, express low-density lipoprotein-related protein 2 (LRP2) that negatively modulate BMP signaling to ensure cell proliferation and neurogenesis
(Gajera et al. 2010). Some of the type B cells have long processes intercalating between adjacent ependymal cells to access the ventricular area (Silva-Vargas et al. 2013; Codega et al. 2014). In contact with the ventricle, these processes express a primary cilium that might play a role in transduction of signals from the CSF. Quiescent type B cells establish adherent and gap junctions with the neighboring ependymal cells and create an apical region that is in direct contact with the CSF (Mirzadeh et al. 2008). These junctions cause polarization of these quiescent type B cells through localization of vascular cell adhesion molecule 1 (VCAM1) on their apical regions. Secretion of Il1-b, a CSFborne factor, regulates the expression of VCAM1 and maintains the neural-stem-cell state. Disruption of VCAM1 downstream signaling pathways would result in activation of the dormant NSCs and exit from the ependymal/CSF compartment (Kokovay et al. 2012).

\section{Endothelial Cells and Neurogenesis}

As vasculature enters the brain parenchyma, they lose most of their outer covering layers so that microvasculature are only formed by the endothelial cells interconnected by tight junctions (blood-brain barrier [BBB]) and enwrapped by pericytes (Aird 2007). Outside the endothelial and pericyte cells, a laminin-rich extracellular matrix (ECM) exists that extends from the microvascular plexus to the ependymal cells. The ECM entraps growth factors and anchors stem cells and their progeny to the perivascular niche and the ependymal cell layer (Goldberg and Hirschi 2009). The microvasculature in the SVZ makes a planar plexus to which both stem cells and transit-amplifying cells contact directly at sites devoid of glial end-feet and pericytes. Type B stem cells extend long projections that make stable interactions with endothelial cells, which enforce their quiescence and promote stem-cell identity in the SVZ (Mirzadeh et al. 2008; Tavazoie et al. 2008). Moreover, the niche has access to systemic signals via CSF and blood through an altered BBB in the niche vasculature (Goldberg and Hirschi 2009). Secreted factors, such as pigment epithelium- 
derived factors (PEDFs) and basic fibroblastic factors (b-FGFs) from the endothelial cells in the SVZ stimulates neurogenesis. PEDFs also influence self-renewal of type B cells via Notch signaling pathway (Ramirez-Castillejo et al. 2006). Blood vasculature also provides access to circulating systemic factors, including sex hormones, glucococorticoids, erythropoietins, and prolactins that can affect states of cell quiescence, proliferation, and differentiation.

\section{Niche Innervation and Neurogenesis}

Studies have shown that neural-stem-cell niches are heavily innervated by various kinds of neurons from local or long distance circuitries. For example, the SVZ is rich in nerve endings originating either from the local neural circuitry, such as medium spiny and aspiny GABAergic neurons of the adjacent striatum (Young et al. 2011) or from distant brain regions, such as dopaminergic neurons of the substantia nigra and ventral tegmental area (Hoglinger et al. 2004; Baker et al. 2004), and serotonergic neurons of the raphe nuclei (Tong et al. 2014). $\gamma$-Aminobutyric acid (GABA) is an inhibitory neurotransmitter and its effect on NS/PCs in the SVZ depends on their source and mode of release but overall it maintains a balance in proliferation and modulates the quiescence of NS/PCs in SVZ (Daynac et al. 2013). GABA acts as an excitatory signal for NSCs and immature neuronal cells in SGZ but also as an inhibitory signal for mature neurons (Tozuka et al. 2005). Parvalbumin-expressing interneurons enhance neuronal differentiation of progenitor cells in dentate gyrus of hippocampus (Song et al. 2012). Dopamine is mainly synthesized in the substantia nigra and ventral segmental area and causes NS/PCs proliferation in the SVZ. Ablation of dopaminergic inputs to SVZ results in diminished cell proliferation and neurogenesis (Hoglinger et al. 2004). Moreover, serotonergic system and the raphe nuclei also have positive effects on SVZ and SGZ cell proliferation (Hitoshi et al. 2007; Tong et al. 2014). Interestingly, $5 \mathrm{HT}$ positive axons were also found along the surface of the SVZ ventricular wall. It has been suggested that $5 \mathrm{HT}$ released by supraependy- mal axons activates 5HT2C in choroid plexus cells, causing them to secrete FGF and known to increase V-SVZ proliferation (Soumier et al. 2010).

\section{Microglial Cells and Neurogenesis}

Microglial cells, as the local immune cells of the CNS, are diffusely located in brain and spinal cord. It was first thought that microglial cells are functionally homogenous across all regions of the CNS but studies showed that microglial cells in neurogenic and nonneurogenic regions are different in their proliferation capacity and marker expression on activation (Goings et al. 2006). Studies showed that microglial cells not only play defensive roles in response to inflammatory conditions, secondary to neurological insults and degeneration, they are also involved in migration, proliferation, and differentiation of neural stem and progenitor cells (Walton et al. 2006). For example, environmental enrichment leads to increased neuronal production in the dentate gyrus of the hippocampus and this process is regulated by microglial cell activation (Ziv et al. 2006). Moreover, it was shown that insulin-like growth factor 1 (IGF1) secreting microglial cells in the SVZ of the adult mouse brain are highly proliferative and respond to neurological insults by supporting and promoting neuroblast migration to the site of injury (Ekdahl et al. 2009). It also has been shown that in vitro passaging of the SVZ harvested neural stem and progenitor cells may result in loss of their neurogenic capability but when SVZ-derived microglial cells were supplemented in the culture at each passage, the neurogenic capacity was preserved for an extended period of time (Marshall et al. 2014).

\section{NEUROSPHERE AS AN IN VITRO MODEL FOR ADULT NEUROGENESIS}

Isolated tissue from the SVZ along the entire length of the neuraxis of the neonatal and adult mammalian brain, as well as tissue harvested from different regions of fetal CNS, can grow on plating in a serum-free chemically defined culture system known as the neurosphere assay 
(NSA) and gradually form clonally derived clusters of cells named as the neurospheres (Reynolds et al. 1992; Reynolds and Weiss 1996; Golmohammadi et al. 2008; Azari et al. 2010, 2011c). The NSA has the potential to recapitulate the series of events that occur during in vivo neurogenesis and act a useful in vitro model, but there are some important issues and limitations to this model that need to be considered. First, because bona fide neural stem cells comprise a tiny fraction of cells in the harvested tissue among the overwhelming progenitor cell population, only a tiny fraction of the resulting neurspheres are actually bona fide stem-cell derived (Reynolds and Rietze 2005). Second, bona fide stem-cell-derived neurospheres cannot be distinguished from the progenitor-derived neurospheres based on the shape and size unless cultured for a longer time in a semisolid culture medium that guarantees long-term proliferative capability of the stem-cell-derived neurospheres (Louis et al. 2008; Azari et al. 2011a). Thus, it should be considered that the series of events from a single stem cell (type B cell) to transit-amplifying cells (type C cells) and finally the neuroblast cells (type A) could not be visualized in all neurospheres. Hence, the majority of the resulting neurospheres contain transit-amplifying cells (type C cells) that have a more gliogenic fate than neurogenic cells. Third, as the neurosphere grows in size, it becomes progressively heterogeneous in terms of its cell content. Neurospheres comprise undifferentiated bona fide NSC (if the sphere is stem-cell derived), neuronal and glial restricted progenitor cells, postmitotic neuronal cells, dead or dying cells (because of restricted access to nutrients and oxygen, cells occupying the center of the neurospheres die or differentiate as the neurospheres grow in size) (Bez et al. 2003; Jensen and Parmar 2006). Finally, the NSA medium is a culture system that selects neural stem cells and precursor cells but does not maintain other cellular components of the in vivo stem-cell niche, such as the ependymal cells, endothelial cells, and microglial cells. Consequently, on passaging of the neurospheres, many of these important contributing elements of the in vivo niche are lost and this could, in part, contribute to loss of the neurogenic ability and even the positional identity of the long-term passaged NSCs. It has been shown that even specific astrocytic cells in stem-cell niches are instructive in the process of in vivo neurogenesis (Song et al. 2002).

\section{THE NEUROBLAST ASSAY: DEVELOPMENT OF A MONOLAYER CULTURE OF NSCS AND PRECURSOR CELLS AS AN IN VITRO MODEL FOR ADULT NEUROGENESIS}

As neurospheres do not allow us to evaluate their inner cellular content and to easily determine the stage of differentiation, it is customary to plate whole neurospheres or the single cells obtained from dissociated neurospheres on an ECM-coated substrate in a serum-free or serum-containing medium to study the differentiation capabilities of a given neural stem and progenitor cell population. In this process, the neurospheres or its dissociated cell contents attach to the substrate and migrate, forming a monolayer culture of differentiating neuronal and glial cells. Although this method can be beneficial in screening, the neurogenic or gliogenic effects of particular drugs and small molecule libraries or explore the epigenetic manipulation of neural stem and progenitor cells, it cannot allow the identification of the dynamic processes involved in generation and functional maturation of individual neuronal cells from stem cells. Modification of this culture system was first reported by Scheffler et al. (2005), who developed a monolayer culture system that recapitulated postnatal and adult SVZ neurogenesis, allowing one to monitor the series of events from a glial-like stem cell through to a mature neuron. Similarly, around the same time, we had made the observation that following longterm differentiation of neural-stem-cell progeny using a monolayer approach, a rare population of large undifferentiated blast cells, sitting on top of a protoplasmic astrocyte layer, would begin to divide giving rise to clonal pockets of small blasts cells that would subsequently differentiate into neurons (Fig. 1A). As this was reminiscent of previously described SVZ in vivo neurogenesis, we further characterized this 
A
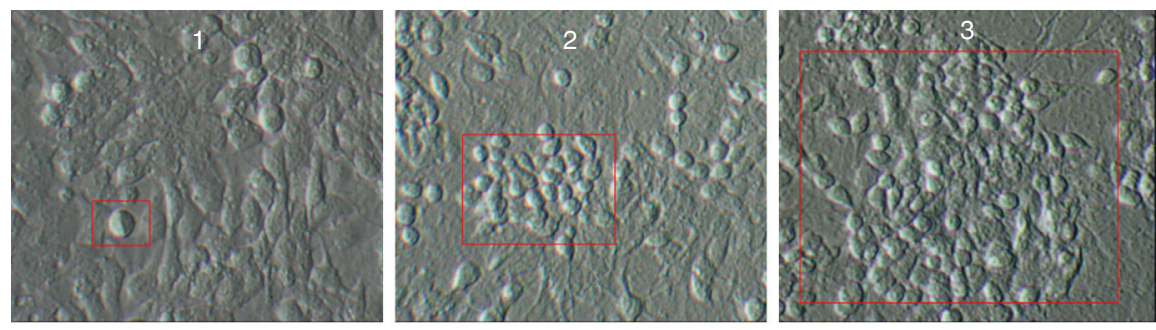

B

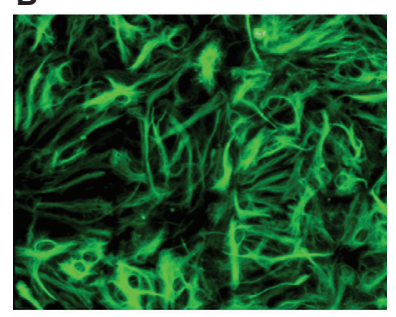

c

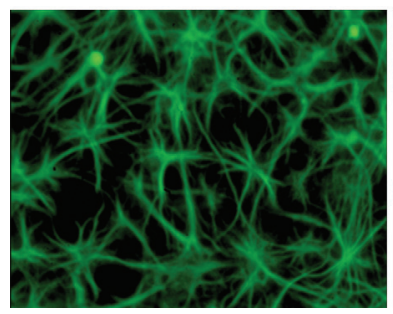

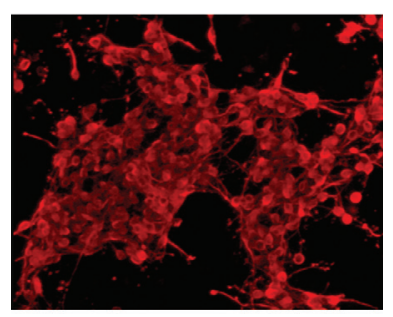

GFAP/B-III tubulin/DAPI
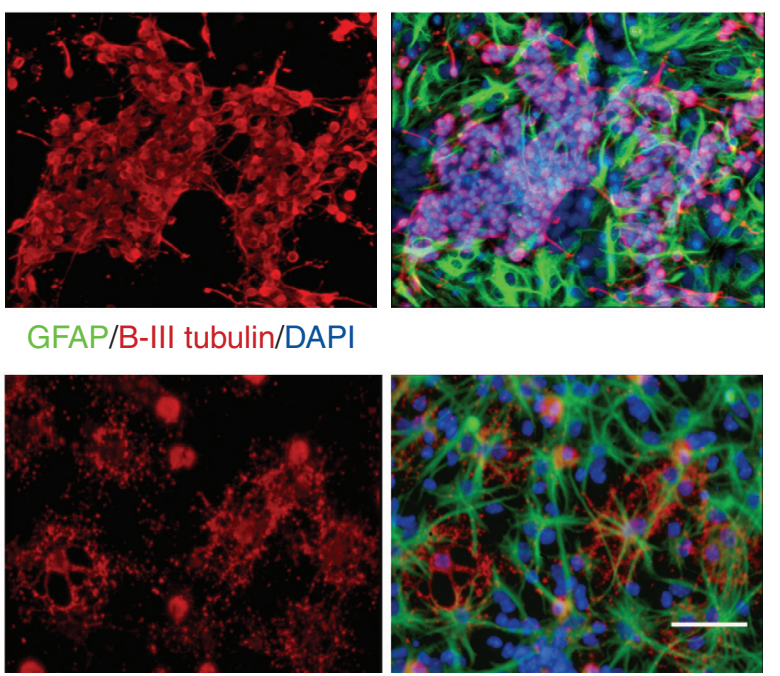

.

GFAP/04/DAPI 
rospheres or monolayer cultures especially after long passages, it is highly recommended to use b-FGF (Raballo et al. 2000), LIF, and DHEA (Suzuki et al. 2004), even with fetal neural stem cells that usually grow well with EGF alone.

\section{Establishing Neurogenic Monolayer Culture}

To generate a monolayer culture that mimics sequential events of adult neurogenesis, plate dissociated single cells at a density of $2-3 \times$ $10^{5}$ cells $/ \mathrm{ml}$ in appropriate culture dishes coated with polyornithine in neural-stem-cell medium supplemented with 5\% fetal bovine serum and the growth factors as mentioned above. Place the culture dish in a $37^{\circ} \mathrm{C}$ humidified incubator with $5 \% \mathrm{CO}_{2}$ for 3 to 4 days so that the cells can proliferate to $90 \%$ confluence. To induce neurogenesis, replace the culture medium with growth-factor-free medium containing 5\% FCS. $24 \mathrm{~h}$ after inducing differentiation, a monolayer of flat amorphous cells underneath and individually scattered round cells on top could be visualized throughout the culture (Fig. 1A1). After an initial 24-h silent period, a series of rapid cell divisions leads to formation of clonal-derived clusters of neuroblasts (Fig. 1A2,1A3,1B). Bromodeoxyuridine (BrdU)-labeling experiments showed that the majority of the neuroblasts are generated on day 3 and 4 after inducing differentiation. Ultrastructural and phenotypic analysis of these individually located cells and their subsequent progeny leading to formation of compacted colonies of small round neuroblasts resemble the mixture of $\mathrm{A}$ and $\mathrm{C}$ cells described in neurogenic niches of adult SVZ (Scheffler et al. 2005). Apart from neuroblasts, this proliferative monolayer culture system also generates $\mathrm{O}_{4}$ expressing oligodendrocytes (Fig. 1C). Further differentiation of these immature $\mathrm{A} 2 \mathrm{~B} 5^{+} /$ nestin $^{+} / \beta$ III tubulin ${ }^{+}$cells in situ using RA or using BMP4 after isolation from their glial bed led to complete maturation and neurite outgrowth and arborization (Scheffler et al. 2005; Azari et al. 2011b). On maturation, these neurons express GAD-65/67 and GABA demonstrating GABAergic interneuron phenotype.
This in vitro monolayer model of adult neurogenesis is a reductionist approach to the complex series of events happening in vivo in neurogenic niches of the SVZ. It is typically observed that the neurogenic capability of neural stem and progenitor cells diminishes dramatically on long-term passaging in vitro (Palmer et al. 1999; Gabay et al. 2003). This could be caused by loss of interactions between niche neural cells and nonneural cells or presence of growth factors at nonphysiological levels as well as absence of factors, such as LIF, that have been shown to guarantee the maintenance of primitive neural stem cells during fetal neural development and in adult stem-cell niches (Sachewsky et al. 2014). This model has the capacity for key players in adult neurogenesis, such as ependymal cells, endothelial cells, microglial cells, and mature neuronal cells of different phenotypes to be supplemented to the neural stem and progenitors to mimic the more complicated in vivo microenvironment. All these cells could be separately prepared and supplemented to the culture of differentiating NSCs to study their interactions with the main neural cell types of the neurogenic niche at different stages of neurogenesis. As an example, in an attempt to dissect differential roles of microglial cells from neurogenic and nonneurogenic regions, we observed that supplementing the SVZ cultures with SVZ-derived microglia would result in sustained levels of neurogenesis, only if the ratio of microglia to total cells stays in a range that mimics their respective in vivo niche (Marshall et al. 2014). Moreover, it was shown recently that direct coculture of endothelial cells with adult SVZ-derived NSCs enforced quiescence and stem-cell identity of SVZ-derived NSCs (Ottone et al. 2014). Similar studies with the aim of determining the individual or collective effects of other key cellular elements of the SVZ with neural stem and progenitor cells would be very interesting using this in vitro adult neurogenesis model.

\section{CONCLUDING REMARKS}

Ongoing adult neurogenesis plays an important role in normal brain health and successful brain 
aging. Although studying this process in animal models offers insights into the human equivalent, it has shortcomings that can be overcome with tissue culture models. Some of these limitations, such as species differences and the complexity of the in vivo environment, can be surmounted by developing simple tissue culture models that allow the use of human cells, greater control over the experimental environment, and direct visualization of neurogenesis in real time. However, many models of neurogenesis better reflect developmental neurogenesis than adult neurogenesis. Building on the pioneering work from Dennis Steindler's laboratory, we have developed a tissue culture model, called the NeuroBlast Assay, that mimics many of the key phenotypic and gene-expression features of in situ neurogenesis and have replicated this using human neural stem cells. Although nearly all tissue culture models can be viewed as an artifact, defining key in vivo characteristics and exploring these in a model system allows one to delineate important cellular and molecular characteristics that will be vital to better understanding and intervening in pathologies that involve adult neurogenesis.

\section{ACKNOWLEDGMENTS}

This work is supported by the Overstreet Foundation and Grant No. 87-4160 from the Shiraz University of Medical Sciences.

\section{REFERENCES}

Aird WC. 2007. Phenotypic heterogeneity of the endothelium. I: Structure, function, and mechanisms. Circ Res 100: $158-173$.

Amor S, Puentes F, Baker D, van der Valk P. 2010. Inflammation in neurodegenerative diseases. Immunology 129: $154-169$.

Araque A, Navarrete M. 2010. Glial cells in neuronal network function. Philos Trans $R$ Soc Lond B Biol Sci 365: 2375-2381.

Azari H. 2013. Isolation and enrichment of defined neural cell populations from heterogeneous neural stem cell progeny. Methods Mol Biol 1059: 95-106.

Azari H, Rahman M, Sharififar S, Reynolds BA. 2010. Isolation and expansion of the adult mouse neural stem cells using the neurosphere assay. J Vis Exp doi: 10.3791/2393.

Azari H, Louis SA, Sharififar S, Vedam-Mai V, Reynolds BA. 2011a. Neural-colony forming cell assay: An assay to dis- criminate bona fide neural stem cells from neural progenitor cells. J Vis Exp doi: 10.3791/2639.

Azari H, Osborne GW, Yasuda T, Golmohammadi MG, Rahman M, Deleyrolle LP, Esfandiari E, Adams DJ, Scheffler B, Steindler DA, et al. 2011b. Purification of immature neuronal cells from neural stem cell progeny. PLoS ONE 6: e20941.

Azari H, Sharififar S, Rahman M, Ansari S, Reynolds BA. 2011c. Establishing embryonic mouse neural stem cell culture using the neurosphere assay. J Vis Exp doi: $10.3791 / 2457$.

Azari H, Sharififar S, Fortin JM, Reynolds BA. 2012. The neuroblast assay: An assay for the generation and enrichment of neuronal progenitor cells from differentiating neural stem cell progeny using flow cytometry. J Vis Exp doi: $10.3791 / 3712$.

Azari H, Sharififar S, Darioosh RP, Fortin JF, Rahman M, Reynolds BA. 2014. Purifying immature neurons from differentiating neural stem cell progeny using a simple shaking method. Stem Cell Res Ther 4: 178.

Baker SA, Baker KA, Hagg T. 2004. Dopaminergic nigrostriatal projections regulate neural precursor proliferation in the adult mouse subventricular zone. Eur J Neurosci 20: $575-579$.

Bez A, Corsini E, Curti D, Biggiogera M, Colombo A, Nicosia RF, Pagano SF, Parati EA. 2003. Neurosphere and neurosphere-forming cells: Morphological and ultrastructural characterization. Brain Res 993: 18-29.

Chojnacki AK, Mak GK, Weiss S. 2009. Identity crisis for adult periventricular neural stem cells: Subventricular zone astrocytes, ependymal cells or both? Nat Rev Neurosci 10: $153-163$.

Codega P, Silva-Vargas V, Paul A, Maldonado-Soto AR, Deleo AM, Pastrana E, Doetsch F. 2014. Prospective identification and purification of quiescent adult neural stem cells from their in vivo niche. Neuron 82: 545-559.

Compagnucci C, Nizzardo M, Corti S, Zanni G, Bertini E. 2014. In vitro neurogenesis: Development and functional implications of iPSC technology. Cell Mol Life Sci 71: $1623-1639$.

Craig CG, Tropepe V, Morshead CM, Reynolds BA, Weiss S, van der Kooy D. 1996. In vivo growth factor expansion of endogenous subependymal neural precursor cell populations in the adult mouse brain. J Neurosci 16: 26492658.

Daynac M, Chicheportiche A, Pineda JR, Gauthier LR, Boussin FD, Mouthon MA. 2013. Quiescent neural stem cells exit dormancy upon alteration of $\mathrm{GABA}_{\mathrm{A}} \mathrm{R}$ signaling following radiation damage. Stem Cell Res 11: 516-528.

Ekdahl CT, Kokaia Z, Lindvall O. 2009. Brain inflammation and adult neurogenesis: The dual role of microglia. Neuroscience 158: 1021-1029.

Elkabetz Y, Panagiotakos G, Al Shamy G, Socci ND, Tabar V, Studer L. 2008. Human ES cell-derived neural rosettes reveal a functionally distinct early neural stem cell stage. Genes Dev 22: 152-165.

Fathi A, Rasouli H, Yeganeh M, Salekdeh GH, Baharvand H. 2015. Efficient differentiation of human embryonic stem cells toward dopaminergic neurons using recombinant LMX1A factor. Mol Biotechnol 57: 184-194. 
Gabay L, Lowell S, Rubin LL, Anderson DJ. 2003. Deregulation of dorsoventral patterning by FGF confers trilineage differentiation capacity on CNS stem cells in vitro. Neuron 40: 485-499.

Gajera CR, Emich H, Lioubinski O, Christ A, Beckervordersandforth-Bonk R, Yoshikawa K, Bachmann S, Christensen EI, Gotz M, Kempermann G, et al. 2010. LRP2 in ependymal cells regulates BMP signaling in the adult neurogenic niche. J Cell Sci 123: 1922-1930.

Gerrard L, Rodgers L, Cui W. 2005. Differentiation of human embryonic stem cells to neural lineages in adherent culture by blocking bone morphogenetic protein signaling. Stem Cells 23: 1234-1241.

Goings GE, Kozlowski DA, Szele FG. 2006. Differential activation of microglia in neurogenic versus non-neurogenic regions of the forebrain. Glia 54: 329-342.

Goldberg JS, Hirschi KK. 2009. Diverse roles of the vasculature within the neural stem cell niche. Regen Med 4: 879-897.

Golmohammadi MG, Blackmore DG, Large B, Azari H, Esfandiary E, Paxinos G, Franklin KB, Reynolds BA, Rietze RL. 2008. Comparative analysis of the frequency and distribution of stem and progenitor cells in the adult mouse brain. Stem Cells 26: 979-987.

Hitoshi S, Maruta N, Higashi M, Kumar A, Kato N, Ikenaka K. 2007. Antidepressant drugs reverse the loss of adult neural stem cells following chronic stress. J Neurosci Res 85: $3574-3585$.

Hoglinger GU, Rizk P, Muriel MP, Duyckaerts C, Oertel WH, Caille I, Hirsch EC. 2004. Dopamine depletion impairs precursor cell proliferation in Parkinson disease. Nat Neurosci 7: 726-735.

Jensen JB, Parmar M. 2006. Strengths and limitations of the neurosphere culture system. Mol Neurobiol 34: 153-161.

Jessberger S, Gage FH. 2014. Adult neurogenesis: Bridging the gap between mice and humans. Trends Cell Biol 24: $558-563$.

Kawasaki H, Mizuseki K, Nishikawa S, Kaneko S, Kuwana Y, Nakanishi S, Nishikawa SI, Sasai Y. 2000. Induction of midbrain dopaminergic neurons from ES cells by stromal cell-derived inducing activity. Neuron 28: 31-40.

Kempermann G, Gast D, Kronenberg G, Yamaguchi M, Gage FH. 2003. Early determination and long-term persistence of adult-generated new neurons in the hippocampus of mice. Development 130: 391-399.

Kettenmann H, Faissner A, Trotter J. 1996. Neuron-glia interactions in homeostasis and degeneration. In Comprehensive human physiology (ed. Greger R, Windhorst U), pp. 533-543. Springer, Berlin.

Koch P, Opitz T, Steinbeck JA, Ladewig J, Brustle O. 2009. A rosette-type, self-renewing human ES cell-derived neural stem cell with potential for in vitro instruction and synaptic integration. Proc Natl Acad Sci 106: 3225-3230.

Kokovay E, Wang Y, Kusek G, Wurster R, Lederman P, Lowry N, Shen Q, Temple S. 2012. VCAM1 is essential to maintain the structure of the SVZ niche and acts as an environmental sensor to regulate SVZ lineage progression. Cell Stem Cell 11: 220-230.

Kriegstein A, Alvarez-Buylla A. 2009. The glial nature of embryonic and adult neural stem cells. Annu Rev Neurosci 32: $149-184$.
Leahy A, Xiong JW, Kuhnert F, Stuhlmann H. 1999. Use of developmental marker genes to define temporal and spatial patterns of differentiation during embryoid body formation. J Exp Zool 284: 67-81.

Levine AJ, Brivanlou AH. 2007. Proposal of a model of mammalian neural induction. Dev Biol 308: 247-256.

Lim DA, Tramontin AD, Trevejo JM, Herrera DG, GarciaVerdugo JM, Alvarez-Buylla A. 2000. Noggin antagonizes BMP signaling to create a niche for adult neurogenesis. Neuron 28: 713-726.

Linker C, Stern CD. 2004. Neural induction requires BMP inhibition only as a late step, and involves signals other than FGF and Wnt antagonists. Development 131: 56715681.

Louis SA, Rietze RL, Deleyrolle L, Wagey RE, Thomas TE, Eaves AC, Reynolds BA. 2008. Enumeration of neural stem and progenitor cells in the neural colony-forming cell assay. Stem Cells 26: 988-996.

Lu HE, Yang YC, Chen SM, Su HL, Huang PC, Tsai MS, Wang TH, Tseng CP, Hwang SM. 2013. Modeling neurogenesis impairment in Down syndrome with induced pluripotent stem cells from Trisomy 21 amniotic fluid cells. Exp Cell Res 319: 498-505.

Marshall GP II, Deleyrolle LP, Reynolds BA, Steindler DA, Laywell ED. 2014. Microglia from neurogenic and nonneurogenic regions display differential proliferative potential and neuroblast support. Front Cell Neurosci 8: 180.

Mirzadeh Z, Merkle FT, Soriano-Navarro M, Garcia-Verdugo JM, Alvarez-Buylla A. 2008. Neural stem cells confer unique pinwheel architecture to the ventricular surface in neurogenic regions of the adult brain. Cell Stem Cell 3: 265-278.

Morrens J, Van Den Broeck W, Kempermann G. 2012. Glial cells in adult neurogenesis. Glia 60: 159-174.

Okabe S, Forsberg-Nilsson K, Spiro AC, Segal M, McKay RD. 1996. Development of neuronal precursor cells and functional postmitotic neurons from embryonic stem cells in vitro. Mech Dev 59: 89-102.

Ottone C, Krusche B, Whitby A, Clements M, Quadrato G, Pitulescu ME, Adams RH, Parrinello S. 2014. Direct cellcell contact with the vascular niche maintains quiescent neural stem cells. Nat Cell Biol 16: 1045-1056.

Palmer TD, Markakis EA, Willhoite AR, Safar F, Gage FH. 1999. Fibroblast growth factor-2 activates a latent neurogenic program in neural stem cells from diverse regions of the adult CNS. J Neurosci 19: 8487-8497.

Perry VH, Teeling J. 2013. Microglia and macrophages of the central nervous system: The contribution of microglia priming and systemic inflammation to chronic neurodegeneration. Semin Immunopathol 35: 601-612.

Raballo R, Rhee J, Lyn-Cook R, Leckman JF, Schwartz ML, Vaccarino FM. 2000. Basic fibroblast growth factor (Fgf2) is necessary for cell proliferation and neurogenesis in the developing cerebral cortex. J Neurosci 20: 5012-5023.

Ramirez-Castillejo C, Sanchez-Sanchez F, Andreu-Agullo C, Ferron SR, Aroca-Aguilar JD, Sanchez P, Mira H, Escribano J, Farinas I. 2006. Pigment epithelium-derived factor is a niche signal for neural stem cell renewal. Nat Neurosci 9: 331-339. 
Reynolds BA, Rietze RL. 2005. Neural stem cells and neurospheres-Re-evaluating the relationship. Nat Methods 2: 333-336.

Reynolds BA, Weiss S. 1996. Clonal and population analyses demonstrate that an EGF-responsive mammalian embryonic CNS precursor is a stem cell. Dev Biol 175: 1-13.

Reynolds BA, Tetzlaff W, Weiss S. 1992. A multipotent EGFresponsive striatal embryonic progenitor cell produces neurons and astrocytes. J Neurosci 12: 4565-4574.

Sachewsky N, Leeder R, Xu W, Rose KL, Yu F, van der Kooy D, Morshead CM. 2014. Primitive neural stem cells in the adult mammalian brain give rise to GFAP-expressing neural stem cells. Stem Cell Rep 2: 810-824.

Scheffler B, Walton NM, Lin DD, Goetz AK, Enikolopov G, Roper SN, Steindler DA. 2005. Phenotypic and functional characterization of adult brain neuropoiesis. Proc Natl Acad Sci 102: 9353-9358.

Schulz TC, Palmarini GM, Noggle SA, Weiler DA, Mitalipova MM, Condie BG. 2003. Directed neuronal differentiation of human embryonic stem cells. BMC Neurosci 4: 27.

Schulz TC, Noggle SA, Palmarini GM, Weiler DA, Lyons IG, Pensa KA, Meedeniya AC, Davidson BP, Lambert NA, Condie BG. 2004. Differentiation of human embryonic stem cells to dopaminergic neurons in serum-free suspension culture. Stem Cells 22: 1218-1238.

Seri B, Garcia-Verdugo JM, Collado-Morente L, McEwen BS, Alvarez-Buylla A. 2004. Cell types, lineage, and architecture of the germinal zone in the adult dentate gyrus. J Comp Neurol 478: 359-378.

Shen Q, Wang Y, Kokovay E, Lin G, Chuang SM, Goderie SK, Roysam B, Temple S. 2008. Adult SVZ stem cells lie in a vascular niche: A quantitative analysis of niche cell-cell interactions. Cell Stem Cell 3: 289-300.

Silva-Vargas V, Crouch EE, Doetsch F. 2013. Adult neura stem cells and their niche: A dynamic duo during homeostasis, regeneration, and aging. Curr Opin Neurobiol 23: $935-942$.

Song H, Stevens CF, Gage FH. 2002. Astroglia induce neurogenesis from adult neural stem cells. Nature 417: 39-44.

Song J, Zhong C, Bonaguidi MA, Sun GJ, Hsu D, Gu Y, Meletis K, Huang ZJ, Ge S, Enikolopov G, et al. 2012. Neuronal circuitry mechanism regulating adult quiescent neural stem-cell fate decision. Nature 489: 150-154.

Soumier A, Banasr M, Goff LK, Daszuta A. 2010. Regionand phase-dependent effects of $5-\mathrm{HT}_{1 \mathrm{~A}}$ and $5-\mathrm{HT}_{2 \mathrm{C}}$ receptor activation on adult neurogenesis. Eur Neuropsychopharmacol 20: 336-345.

Stiles J, Jernigan TL. 2010. The basics of brain development. Neuropsychol Rev 20: 327-348.

Suzuki M, Wright LS, Marwah P, Lardy HA, Svendsen CN. 2004. Mitotic and neurogenic effects of dehydroepiandrosterone (DHEA) on human neural stem cell cultures derived from the fetal cortex. Proc Natl Acad Sci 101: 3202-3207.
Swistowska AM, da Cruz AB, Han Y, Swistowski A, Liu Y, Shin S, Zhan M, Rao MS, Zeng X. 2010. Stage-specific role for shh in dopaminergic differentiation of human embryonic stem cells induced by stromal cells. Stem Cells Dev 19: $71-82$.

Tavazoie M, Van der Veken L, Silva-Vargas V, Louissaint M, Colonna L, Zaidi B, Garcia-Verdugo JM, Doetsch F. 2008. A specialized vascular niche for adult neural stem cells. Cell Stem Cell 3: 279-288.

Tong CK, Chen J, Cebrian-Silla A, Mirzadeh Z, Obernier K, Guinto CD, Tecott LH, Garcia-Verdugo JM, Kriegstein A, Alvarez-Buylla A. 2014. Axonal control of the adult neural stem cell niche. Cell Stem Cell 14: 500-511.

Tozuka Y, Fukuda S, Namba T, Seki T, Hisatsune T. 2005. GABAergic excitation promotes neuronal differentiation in adult hippocampal progenitor cells. Neuron 47: 803815.

Vazin T, Chen J, Lee CT, Amable R, Freed WJ. 2008. Assessment of stromal-derived inducing activity in the generation of dopaminergic neurons from human embryonic stem cells. Stem Cells 26: 1517-1525.

Velasco I, Salazar P, Giorgetti A, Ramos-Mejia V, Castano J, Romero-Moya D, Menendez P. 2014. Concise review: Generation of neurons from somatic cells of healthy individuals and neurological patients through induced pluripotency or direct conversion. Stem Cells 32: 2811-2817.

Walton NM, Sutter BM, Laywell ED, Levkoff LH, Kearns SM, Marshall GP II, Scheffler B, Steindler DA. 2006. Microglia instruct subventricular zone neurogenesis. Glia 54: $815-825$.

Watanabe K, Kamiya D, Nishiyama A, Katayama T, Nozaki S, Kawasaki H, Watanabe Y, Mizuseki K, Sasai Y. 2005. Directed differentiation of telencephalic precursors from embryonic stem cells. Nat Neurosci 8: 288-296.

Ying QL, Stavridis M, Griffiths D, Li M, Smith A. 2003. Conversion of embryonic stem cells into neuroectodermal precursors in adherent monoculture. Nat Biotechnol 21: 183-186.

Young SZ, Taylor MM, Bordey A. 2011. Neurotransmitters couple brain activity to subventricular zone neurogenesis. Eur J Neurosci 33: 1123-1132.

Zabel MK, Kirsch WM. 2013. From development to dysfunction: Microglia and the complement cascade in CNS homeostasis. Ageing Res Rev 12: 749-756.

Zeng X, Cai J, Chen J, Luo Y, You ZB, Fotter E, Wang Y, Harvey B, Miura T, Backman C, et al. 2004. Dopaminergic differentiation of human embryonic stem cells. Stem Cells 22: 925-940.

Zhang SC, Wernig M, Duncan ID, Brustle O, Thomson JA. 2001. In vitro differentiation of transplantable neural precursors from human embryonic stem cells. Nat Biotechnol 19: 1129-1133.

Ziv Y, Ron N, Butovsky O, Landa G, Sudai E, Greenberg N, Cohen H, Kipnis J, Schwartz M. 2006. Immune cells contribute to the maintenance of neurogenesis and spatial learning abilities in adulthood. Nat Neurosci 9: 268-275. 


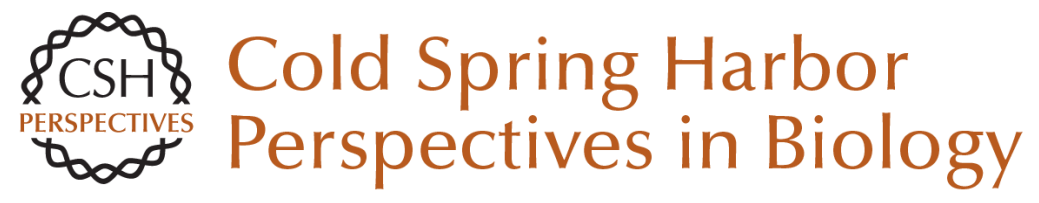

\section{In Vitro Models for Neurogenesis}

Hassan Azari and Brent A. Reynolds

Cold Spring Harb Perspect Biol 2016; doi: 10.1101/cshperspect.a021279 originally published online October 5, 2015

\section{Subject Collection Neurogenesis}

Adult Neurogenesis and Psychiatric Disorders Eunchai Kang, Zhexing Wen, Hongjun Song, et al.

Neuronal Circuitry Mechanisms Regulating Adult Mammalian Neurogenesis Juan Song, Reid H.J. Olsen, Jiaqi Sun, et al.

Neurogenesis in the Developing and Adult Brain

--Similarities and Key Differences

Magdalena Götz, Masato Nakafuku and David Petrik

Genetics and Epigenetics in Adult Neurogenesis Jenny Hsieh and Xinyu Zhao

The Adult Ventricular-Subventricular Zone (V-SVZ) and Olfactory Bulb (OB) Neurogenesis Daniel A. Lim and Arturo Alvarez-Buylla

Diversity of Neural Precursors in the Adult Mammalian Brain Michael A. Bonaguidi, Ryan P. Stadel, Daniel A. Berg, et al.

Detection and Phenotypic Characterization of Adult Neurogenesis $H$. Georg Kuhn, Amelia J. Eisch, Kirsty Spalding, et al.

Maturation and Functional Integration of New Granule Cells into the Adult Hippocampus Nicolas Toni and Alejandro F. Schinder
Adult Olfactory Bulb Neurogenesis

Pierre-Marie Lledo and Matt Valley

Adult Neurogenesis in Fish Julia Ganz and Michael Brand

In Vitro Models for Neurogenesis Hassan Azari and Brent A. Reynolds

Engineering of Adult Neurogenesis and Gliogenesis

Benedikt Berninger and Sebastian Jessberger

Computational Modeling of Adult Neurogenesis James B. Aimone

Control of Adult Neurogenesis by Short-Range Morphogenic-Signaling Molecules Youngshik Choe, Samuel J. Pleasure and Helena Mira

Adult Neurogenesis: An Evolutionary Perspective Gerd Kempermann

Epilepsy and Adult Neurogenesis

Sebastian Jessberger and Jack M. Parent

For additional articles in this collection, see http://cshperspectives.cshlp.org/cgi/collection/

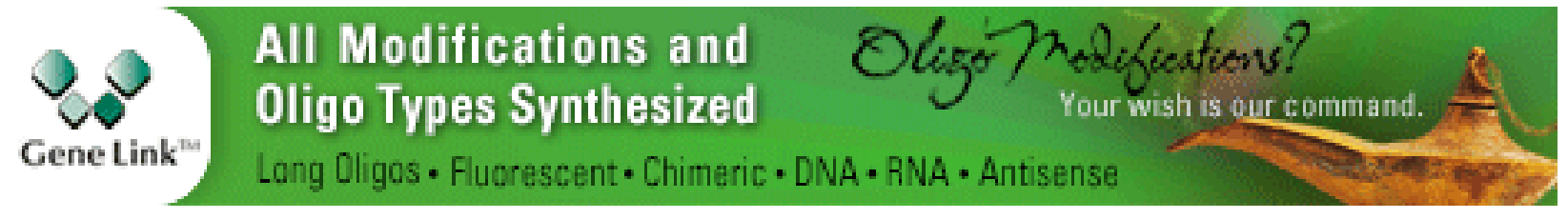


For additional articles in this collection, see http://cshperspectives.cshlp.org/cgi/collection/

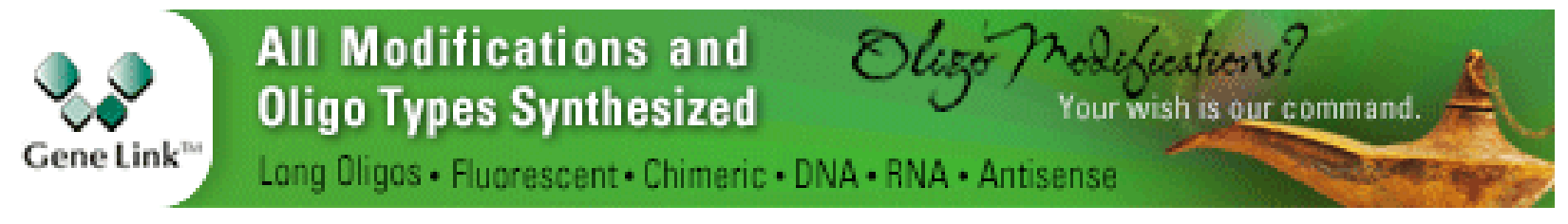

Copyright @ 2016 Cold Spring Harbor Laboratory Press; all rights reserved 